\title{
IN VITRO ASSESSMENT OF DIET-DERIVED PHYTOCHEMICALS ON PSA SECRETION
}

\section{Onuoha Chinyere $^{1}$ and Ikimi Charles German ${ }^{2}$}

${ }^{1}$ Department of Biochemistry, School of Biological Sciences, Federal University of Technology, Owerri, Imo State, Nigeria

E-mail: chizyonu@gmail.com

${ }^{2}$ Department of Biochemistry, Faculty of Science, Federal University Otuoke, Bayelsa State, Nigeria

Email: ikimicg@fuotuoke.edu.ng

Cite this article:

Onuoha C., Ikimi C.G. (2021), In Vitro Assessment of DietDerived Phytochemicals on PSA Secretion. African Journal of Biology and Medical Research 4(3), 9-16. DOI: $10.52589 /$ AJBMRWVEKSXXJ.

\section{Manuscript History}

Received: 1 May 2021

Accepted: 21 May 2021

Published: 2 June 2021

Copyright $($ C) 2020 The Author(s). This is an Open Access article distributed under the terms of Creative Commons AttributionNonCommercial-NoDerivatives 4.0 International (CC BY-NC-ND 4.0 ), which permits anyone to share, use, reproduce and redistribute in any medium, provided the original author and source are credited.
ABSTRACT: Prostate cancer $(\mathrm{PCa})$ is increasingly a global public health burden. The prostate specific antigen (PSA) is the major biomarker for diagnosing and managing PCa. Due to the importance of PSA as a biomarker and as a downstream product of the androgen receptor $(A R)$, it was imperative to expose LNCaP cells to selective diet-derived phytochemicals and investigate the effect on PSA protein secretion. The phytochemicals: Curcumin, 3,3'-Diindolylmethane (DIM) and Epigallcatechin-3-gallate (EGCG) were utilised singly and in paired combinations as in vitro treatments. The ELISA technique was utilised to assess secreted PSA levels. Results obtained indicated that DIM posed inhibitory effects to PSA production and secretion. Uniquely, DIM lowered PSA levels significantly when compared to curcumin and EGCG. This finding corroborates with previous reports where DIM was observed to inhibit AR protein expression. It is suggestive that DIM targets the androgen receptor and its downstream pathway that produces PSA. In conclusion, DIM may hold overwhelming potential chemoprevention and management of $P C a$, and can be harnessed for enhanced clinical applications.

KEYWORDS: Prostate Cancer, Prostate Specific Antigen, 3,3'diindolylmethane, ELISA, Chemoprevention 


\section{INTRODUCTION}

$\mathrm{PCa}$ is a disease that affects many males in Nigeria [Akinremi et al., 2011]. This disease exhibits two phenotypes, the slow-growing PCa type and the aggressive type. In many cases, the slow-growing type does not kill the patient, but dies with the patient, while the aggressive type can be fast-growing and fatal. Many patients with PSA levels above $4 \mathrm{ng} / \mathrm{mL}$ are advised for further examination which involves a DRE and prostate tissue biopsy [Farolfi et al., 2018; Traynor et al., 2020]. Currently, treatment modalities include surgical options such as radical prostatectomy, endocrine therapy like orchidectomy, and others such as radiotherapy, brachytherapy and chemotherapy [Ye et al., 2020].

In desperate efforts for a specific biomarker for PCa, the PSA was discovered. Prior to the discovery of PSA, the prostatic acid phosphatase (PAP) was identified and used for PCa diagnosis and staging. The use of PAP was discontinued in the aftermath of PSA discovery. In 1979, Wang and colleagues isolated a 33-KD glycoprotein that is highly specific to the prostate than PAP. The PSA protein is secreted into the bloodstream and the levels can be detected and measured with low invasiveness [Traynor et al., 2020]. PSA is a downstream target protein of the androgen receptor (AR). The production and secretion of PSA into the bloodstream indicates increased AR-induced proliferation of prostate cells [Bryce et al., 2017]. Although normal prostate tissues and PCa tissues produce PSA, the presence of basal cells in normal prostate causes a retention of PSA, while the lack or reduced numbers of basal cells as observed in PCa causes a leak of PSA into the bloodstream, this thus results in increased levels of PSA during abnormalities associated with the prostate [Zheng et al., 2020].

The PSA has a unique role and is a major diagnostic biomarker for $\mathrm{PCa}$, it is a standard monitoring tool for PCa management [Bryce et al., 2017; Traynor et al., 2020]. Raised PSA levels does not always indicate PCa, but possibly a non-cancerous enlargement or inflammation of the prostate. PSA levels above $4 \mathrm{ng} / \mathrm{mL}$ may indicate progressive PCa, prostatitis or benign prostatic hyperplasia (BPH). After a radical prostatectomy procedure, PSA levels above 0.2 $\mathrm{ng} / \mathrm{mL}$ may indicate biochemical recurrence, a poor post-operative outcome [Farolfi et al., 2018; Tikkinen et al., 2018; Traynor et al., 2020].

Chemoprevention is a strategic use of nutritive or chemical agents that possess the capability to inhibit or delay or reverse the process of carcinogenesis [Wattenberg, 1985; Greenwald et al., 1995]. Epidemiological studies have linked dietary factors to low incidences of PCa. The cultural consumption of unique phytochemicals in wholesome food has been reported as reasons for the lowest PCa incidences in Asia and Africa [Kubatka et al., 2020]. Many phytochemicals are effective in inhibiting $\mathrm{PCa}$ cellular growth/proliferation [IbeawuchiOnuoha, 2016], triggering cell cycle arrest [Ibeawuchi-Onuoha and Anyiam, 2017] and instigating apoptosis [Onuoha and Ikimi, 2019].

In this study, Curcumin, DIM and EGCG were selected for in vitro investigation, to determine effect on secreted PSA levels of LNCaP cell lines. Curcumin is a polyphenol obtained from Curcuma longa Linn commonly called turmeric. Turmeric is a well-known food additive in Asian cuisine [Yang et al., 2017]. DIM is a polyphenol metabolite from indole-3-carbinol (I3C) hydrolysis [Bradlow and Zeligs, 2010] and obtained from cruciferous vegetables such as cabbages, brussel sprouts and broccoli [Li and Sarkar, 2016]. EGCG is another polyphenol that is obtained from green tea and well-consumed in Asia and the green tea culture is becoming acceptable globally [Miyate et al., 2019]. This study attempts to investigate the effect of 
curcumin, DIM or EGCG and their paired combinations on PSA production and secretion of LNCaP cell lines.

\section{METHODOLOGY}

Treatments used in this study included curcumin, DIM and EGCG. Treatments utilised in this study and Dimethyl sulfoxide (DMSO) were purchased from Sigma-Aldrich (Germany). The human lymph node prostate carcinoma cell lines (LNCaP) were obtained from American Type Culture Collection (ATCC) (Virginia, USA). The cell culture media was obtained from Invitrogen (Paisley, UK) and Sigma-Aldrich (Germany).

\section{Cell Culture and Treatment}

The human lymph node prostatic carcinoma cells, LNCaP were grown and maintained in RPMI (Roswell Park Memorial Institute) 1640 medium with 10\% v/v foetal calf serum (FCS) (Invitrogen, Paisley, UK). All treatments were prepared in DMSO, which constituted less than $0.1 \% \mathrm{v}: \mathrm{v}$ to culture media used. Control treatments contained equivalent concentration of DMSO and treatment of cells was designed as thus: curcumin $(5 \mu \mathrm{m}), \mathrm{DIM}(50 \mu \mathrm{M})$ and EGCG $(30 \mu \mathrm{M})$ and the combinations curcumin $(5 \mu \mathrm{m})+$ DIM $(50 \mu \mathrm{M})$, curcumin $(5 \mu \mathrm{M})+$ EGCG $(30 \mu \mathrm{M})$ and DIM $(50 \mu \mathrm{M})+$ EGCG $(30 \mu \mathrm{M})$ [Ibeawuchi-Onuoha, 2016]. Concentration doses were obtained by adjusting $\mathrm{IC}_{50}$ values from previous published studies for this experimental design [Shenouda et al., 2004; Garikapathy et al., 2006; Kimura et al., 2007; Valentini et al., 2009].

LNCaP cells were washed with PBS, trypsinised, centrifuged, re-suspended in sterile warm 10\% FCS media (RPMI 1640) and counted with a Coulter particle counter and size analyzer (Beckman coulter, Wycombe, UK). Cell count results were adjusted to obtain $1 \times 10^{4}$ cells per well. $1 \times 10^{4}$ cells were seeded into 24 well plates and incubated for 48 hours at $37^{\circ} \mathrm{C}$ and $5 \%$ $\mathrm{CO}_{2}$. After the period of cell adherence, $1 \mathrm{ml}$ of media containing concentrations of curcumin, DIM, EGCG and the paired combinations of curcumin + DIM, curcumin + EGCG, DIM + EGCG were added to respective wells, in triplicates. Cells were incubated further for 144 hours at $37^{\circ} \mathrm{C}$ and $5 \% \mathrm{CO}_{2}$. After the incubation period, supernatant media was aspirated and stored at $-80^{\circ} \mathrm{C}$ prior to use for PSA-ELISA (Enzyme Linked Immunoassay Specific Antigen) assay.

\section{PSA-ELISA assay}

The PSA levels were evaluated with the use of the Quantikine ${ }^{\circledR}$ Human KLK3/PSA immunoassay kit (RnD systems, Minneapolis, USA). Samples and reagents were brought to room temperature before use. $100 \mu \mathrm{l}$ of cell culture supernatant media samples were added into each well in triplicates in 96 well plates. Absorbance of the plates were read at $450 \mathrm{~nm}$ and 540 $\mathrm{nm}$ wavelengths, within 30 minutes using a microplate reader. A graph of absorbance and concentration of the standards was determined and the unknown PSA concentration was extrapolated and deduced from the Standard curve. 


\section{RESULTS}

The effect of curcumin, DIM, EGCG and their combinations were examined on PSA secretion levels from LNCaP cells with the ELISA technique (Human KLK3/PSA Immunoassay, R\&D Systems, Abingdon, UK). All treated and controls were assayed in triplicates. The Standard from kit were also assayed in triplicates. Absorbance readings were obtained at $450 \mathrm{~nm}$ and $540 \mathrm{~nm}$. Using the kit's standard operating protocol, the mean difference of absorbance values $(450 \mathrm{~nm}-540 \mathrm{~nm})$ for the standards were plotted against the standard concentrations of $0,0.94$, $1.88,3.75 .7 .5,15,30$ and $60 \mathrm{ng} / \mathrm{ml}$ to generate a standard curve (Figure 1).

In addition, the mean difference of absorbance values (450 nm - $540 \mathrm{~nm}$ ) were obtained for treated and untreated media samples (Figure 2). From Figure 1 and generated equation, The relative PSA concentrations were deduced. The relationship between investigated treatments and absolute PSA concentrations was displayed in Figure 3. After 144 hours, there was a significant decrease in PSA levels following the treatments of DIM, C $+\mathrm{D}$ and D $+\mathrm{E}(P<$ $0.05)$.

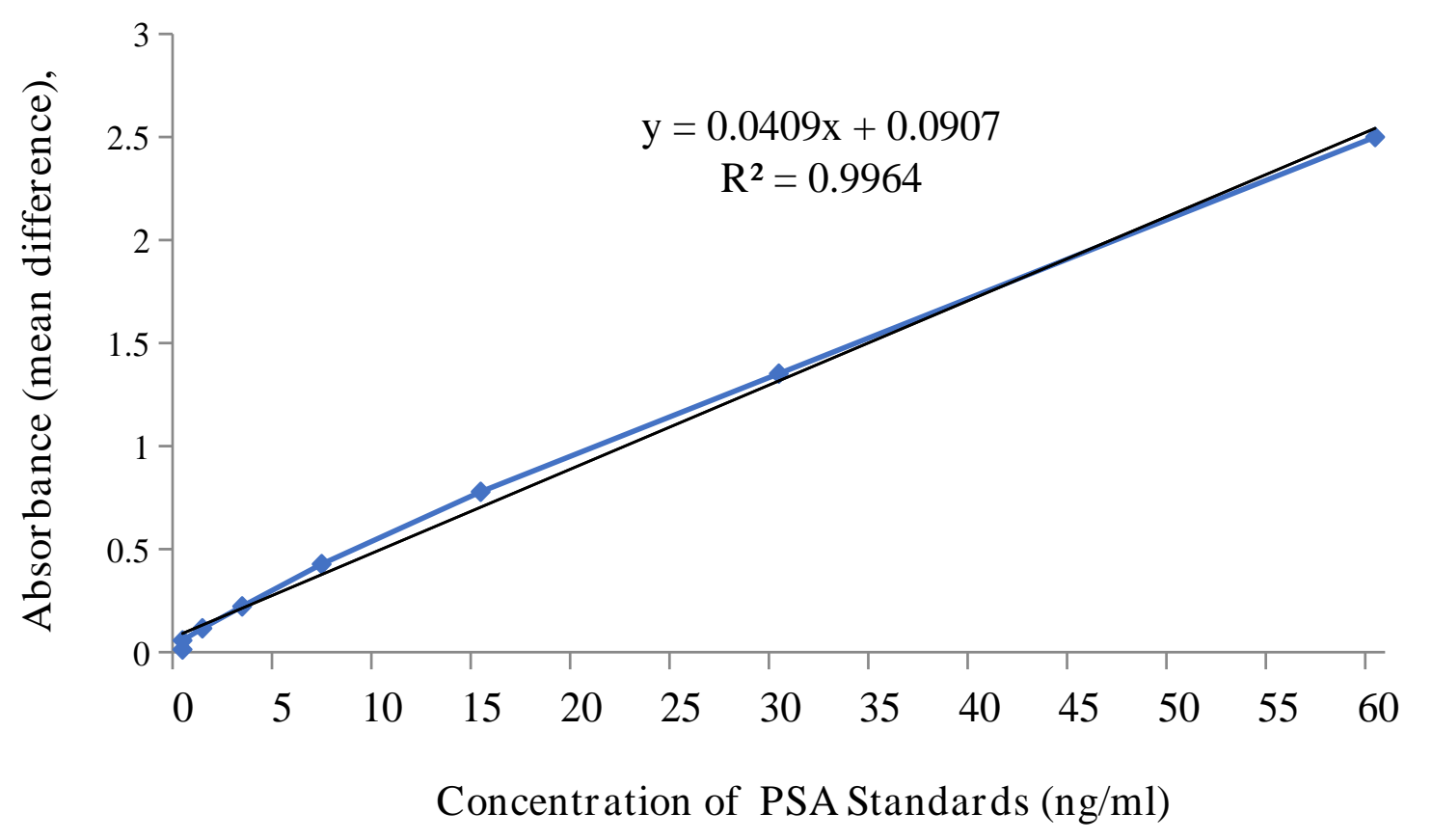

Figure 1: Standard curve generated for the determination of absolute PSA concentration. Mean difference of absorbance for each standard concentration $(0,0.94$, $1.88,3.75,7.5,15,30 \mathrm{ng} / \mathrm{ml}$ ) to obtain a linear graph. 


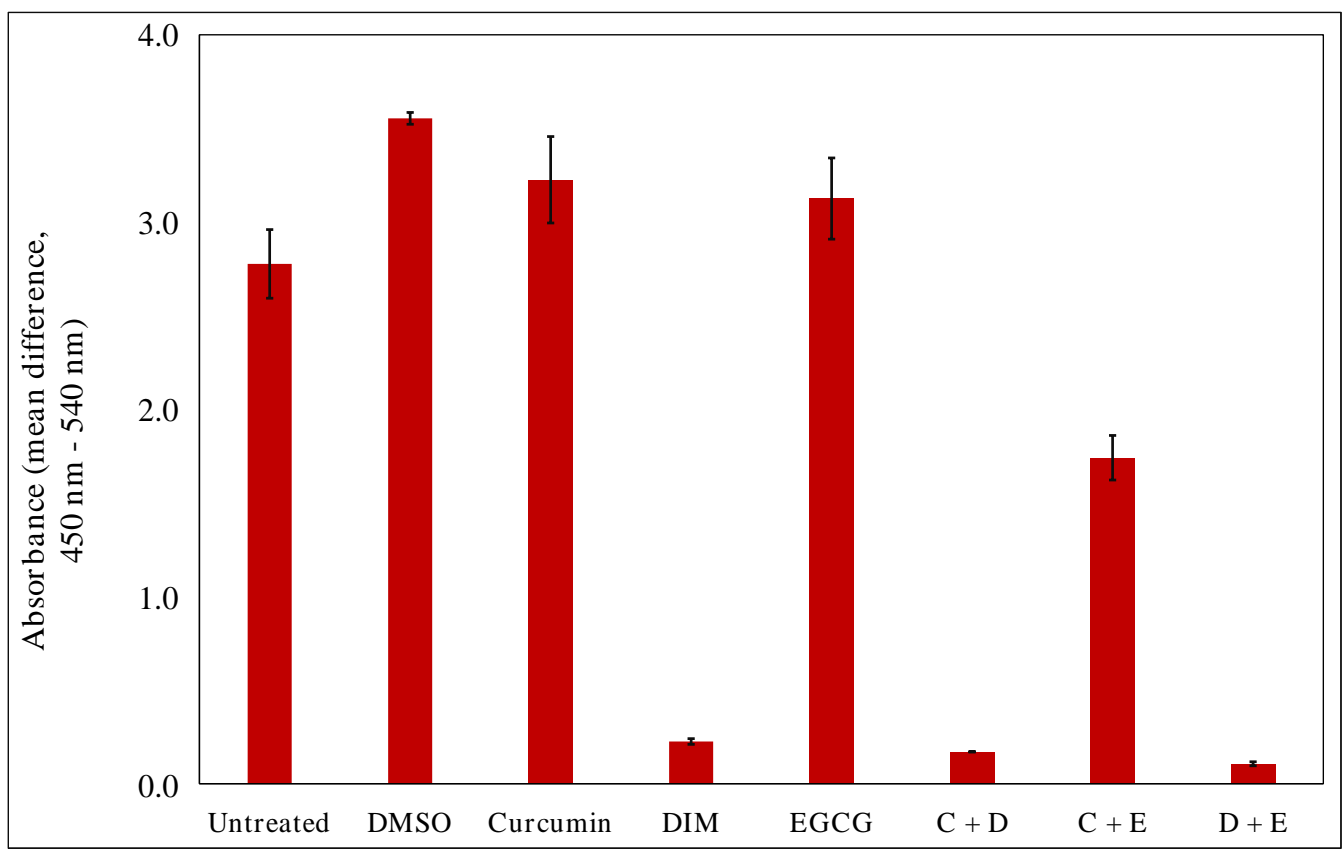

Figure 2: Mean difference of absorbance of treated and control assayed samples. Media samples were employed for this assay and analysed in triplicates. Columns are mean differences of absorbance while bars are \pm standard deviation.

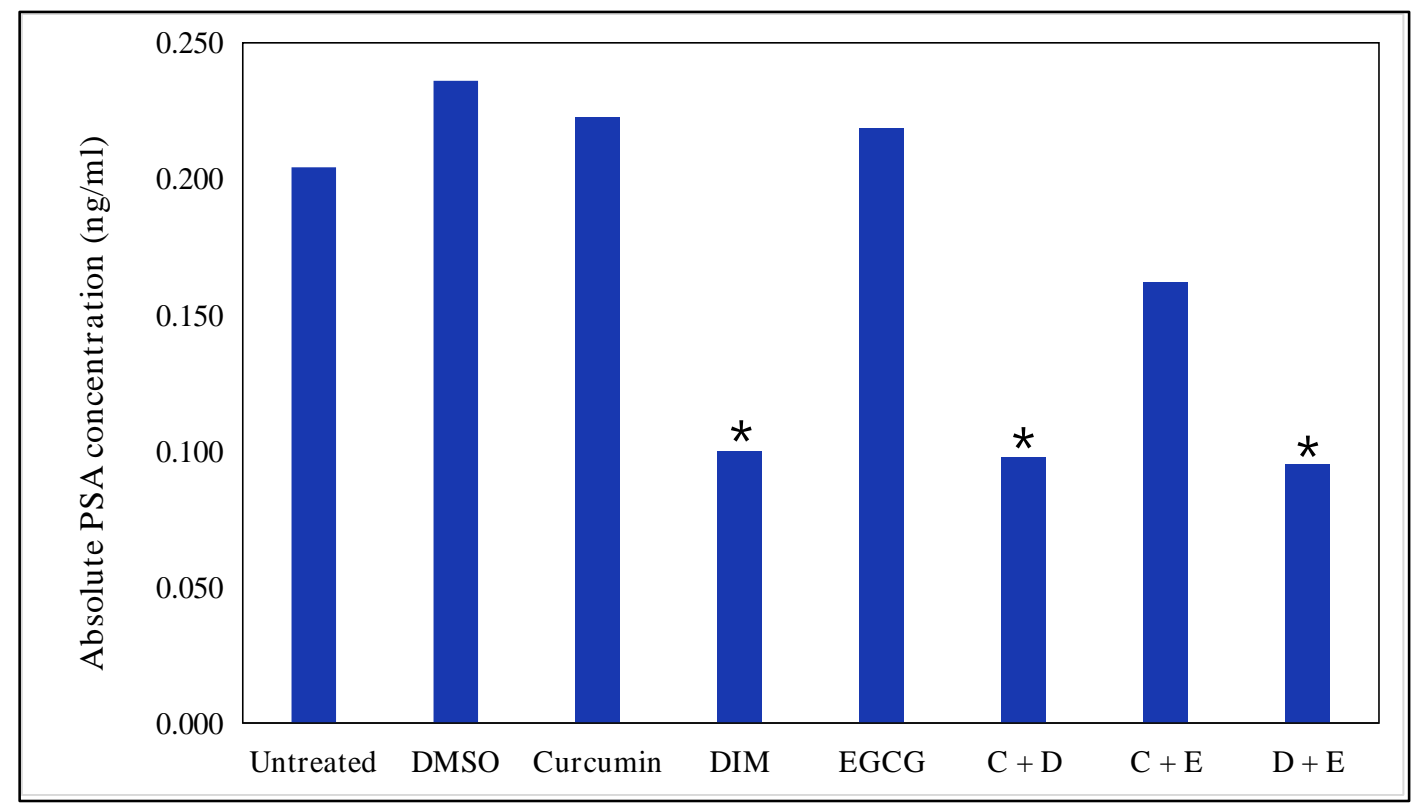

Figure 3: Absolute PSA concentration of treated and control assayed samples. Effect of curcumin, DIM, EGCG and their paired combinations on the secreted levels of PSA by LNCaP cells. $(*) P<0.05$ when compared to DMSO (control), as determined by the repeated measures one-way ANOVA followed by a post-hoc Tukey test. 


\section{DISCUSSION}

This study aimed at evaluating the effect of selected diet-derived phytochemicals on levels of secreted PSA proteins from LNCaP cells. The main finding of this study is that the in vitro treatments of DIM, C + D and D + E respectively on LNCaP cells caused significant lower secretions of PSA. DIM stood out as the polyphenol with the most potential in the inhibition of PSA.

PSA belongs to the human kallikrein family of serine proteases and are initially synthesised as preproenzymes, and needs to be activated in two steps. PSA is activated firstly with the proteolytic removal of a short amino acid chain at the N-terminus and then with subsequent activation by some proteases, either the matrix metalloproteinases (MMPs) or urinary plasminogen activator (uPA). Functionally, PSA inhibits the coagulation of the seminal fluid [Saxena et al., 2012]. The growth and development of normal prostate and PCa is largely dependent on AR, its role is crucial in prostate organogenesis [Zhang et al., 2018]. AR is responsible for PSA secretion, and PSA remains a very important diagnostic biomarker.

PSA is uniquely investigated in this study because it is prostate-specific and regulated by androgens. Increased levels of PSA indicate abnormalities of the prostate. Since DIM and paired combination treatments containing DIM were capable of inhibiting or lowering PSA levels, this may indicate effectiveness of DIM to prostate carcinogenesis and development. The observation from this study corroborates with previous findings: the polyphenol DIM, was found to ideally inhibit LNCaP cell growth and proliferation maximally when compared with curcumin and EGCG [Ibeawuchi-Onuoha, 2016], in a different study that utilised the western blotting technique, the polyphenol DIM played an inhibitory role on AR protein expression [Onuoha and Anyiam, 2021]. With DIM's capabilities to inhibit LNCaP growth and target the AR and potentially inhibit AR function, it is suggestive that DIM inhibits PSA secretion because it targets AR, the up-stream protein of PSA.

\section{CONCLUSION}

The comparative investigation of curcumin, DIM and EGCG phytochemicals on LNCaP cells indicate that DIM has the most capabilities to inhibit AR and its downstream protein, PSA. The future of DIM as a potential chemopreventive regime lies in its pharmaceutical acceptability and development. 


\section{REFERENCES}

Akinremi, T. O., Ogo, C. N., and Olutunde, A. O. (2011). Review of prostate cancer research in Nigeria. Infectious agents and cancer, BioMed Central, 6(2), 1-4.

Bradlow, H. L., and Zeligs, M. A. (2010). Diindolylmethane (DIM) spontaneously forms from indole-3-carbinol (I3C) during cell culture experiments. In Vivo, 24(4), 387-391.

Bryce, A. H., Alumkal, J. J., Armstrong, A., Higano, C. S., Iversen, P., Sternberg, C. N., ... and Beer, T. M. (2017). Radiographic progression with nonrising PSA in metastatic castration-resistant prostate cancer: post hoc analysis of PREVAIL. Prostate cancer and prostatic diseases, 20(2), 221-227.

Farolfi, A., Ceci, F., Castellucci, P., Graziani, T., Siepe, G., Lambertini, A., ... and Fanti, S. (2019). 68 Ga-PSMA-11 PET/CT in prostate cancer patients with biochemical recurrence after radical prostatectomy and PSA $<0.5 \mathrm{ng} / \mathrm{ml}$. Efficacy and impact on treatment strategy. European journal of nuclear medicine and molecular imaging, 46(1), 11-19.

Garikapaty, V. P., Ashok, B. T., Tadi, K., Mittelman, A., and Tiwari, R. K. (2006). Synthetic dimer of indole-3-carbinol: Second generation diet derived anti-cancer agent in hormone sensitive prostate cancer. The Prostate, 66(5), 453-462.

Greenwald, P., Kelloff, G., Burch-Whitman, C., and Kramer, B. S. (1995). Chemoprevention. CA: a cancer journal for clinicians, 45(1), 31-49.

Ibeawuchi-Onuoha, C. (2016). Combinations of selected dietderived agents show enhanced growth inhibition of LNCaP cell lines. International Journal, 2(1), 20-25.

Ibeawuchi-Onuoha, C., and Anyiam, I. V. (2017). Cell cycle distribution response of human lymph node prostate carcinoma ( $\mathrm{LNCaP})$ cell line to selected diet-derived agents. Biokemistri, 29(4), 146-150.

Kimura, K., Itakura, Y., Goto, R., Tojima, M., Egawa, N., and Yoshihama, M. (2007). Inhibition of 17alpha-hydroxylase/C17,20-lyase (CYP17) from rat testis by green tea catechins and black tea theaflavins. Bioscience, Biotechnology, and Biochemistry, 71(9), 2325-2328.

Kubatka, P., Liskova, A., Kello, M., Mojzis, J., Solar, P., Solarova, Z., ... and Kabir, Y. (2020). Plant-derived functional foods with chemopreventive and therapeutic potential against breast cancer: A review of the preclinical and clinical data. Functional Foods in Cancer Prevention and Therapy, 283-314.

Li, Y., and Sarkar, F. H. (2016). Role of BioResponse 3,3'-diindolylmethane in the treatment of human prostate cancer: Clinical experience. Medical Principles and Practice:

International Journal of the Kuwait University, Health Science Centre, 25 Suppl 2, 11 17.

Miyata, Y., Shida, Y., Hakariya, T., and Sakai, H. (2019). Anti-cancer effects of green tea polyphenols against prostate cancer. Molecules, 24(1), 193.

Onuoha, C., and Anyiam, V. I. (2021). Western blot evaluation of LNCaP cells in response to selective phytochemical treatments. African Journal of Biology and Medical Research, $4(2), 1-12$.

Onuoha, C., and Ikimi, C. G. (2019). Induction of Apoptosis by selected diet-derived phytochemicals on LNCaP cell line. International Journal, 5(2), 85-89.

Saxena, P., Trerotola, M., Wang, T., Li, J., Sayeed, A., VanOudenhove, J., ... and Languino, L. R. (2012). PSA regulates androgen receptor expression in prostate cancer cells. The Prostate, 72(7), 769-776. 
Shenouda, N. S., Zhou, C., Browning, J. D., Ansell, P. J., Sakla, M. S., Lubahn, D. B., and MacDonald, R. S. (2004). Phytoestrogens in common herbs regulate prostate cancer cell growth in vitro. Nutrition and Cancer, 49(2), 200-208.

Tikkinen, K. A., Dahm, P., Lytvyn, L., Heen, A. F., Vernooij, R. W., Siemieniuk, R. A., ... and Agoritsas, T. (2018). Prostate cancer screening with prostate-specific antigen (PSA) test: a clinical practice guideline. Bmj, 362 .

Traynor, S. M., Pandey, R., Maclachlan, R., Hosseini, A., Didar, T. F., Li, F., and Soleymani, L. (2020). Recent Advances in Electrochemical Detection of Prostate Specific Antigen (PSA) in Clinically-Relevant Samples. Journal of The Electrochemical Society, 167(3), 037551.

Valentini, A., Conforti, F., Crispini, A., De Martino, A., Condello, R., Stellitano, C., ... and Pucci, D. (2009). Synthesis, oxidant properties, and antitumoral effects of a heteroleptic palladium (II) complex of curcumin on human prostate cancer cells. J.Med.Chem, 52(2), 484-491.

Wattenberg, L. W. (1985). Chemoprevention of cancer. Cancer Res, 45(1), 1-8.

Ye, M., Tian, H., Lin, S., Mo, J., Li, Z., Chen, X., and Liu, J. (2020). Resveratrol inhibits proliferation and promotes apoptosis via the androgen receptor splicing variant 7 and PI3K/AKT signaling pathway in LNCaP prostate cancer cells. Oncology Letters, 20(5), $1-1$.

Zhang, Y., Pitchiaya, S., Cieslik, M., Niknafs, Y. S., Tien, J. C., Hosono, Y., ... and Chinnaiyan, A. M. (2018). Analysis of the androgen receptor-regulated lncRNA landscape identifies a role for ARLNC1 in prostate cancer progression. Nature Genetics, 50(6), 814-824.

Zheng, Z., Zhou, Z., Yan, W., Zhou, Y., Chen, C., Li, H., and Ji, Z. (2020). Tumor characteristics, treatments, and survival outcomes in prostate cancer patients with a PSA level< $4 \mathrm{ng} / \mathrm{ml}$ : a population-based study. BMC cancer, 20, 1-7. 